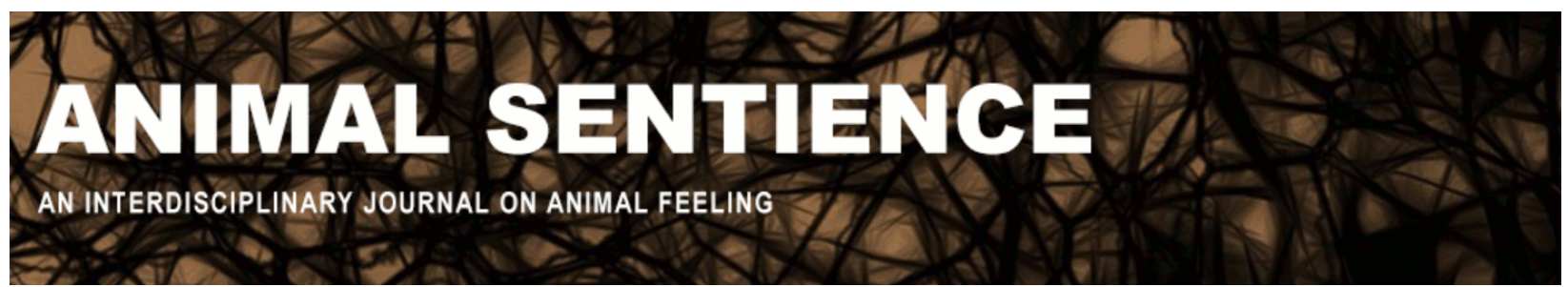

Sneddon, Lynne U.; Lopez-Luna, Javier; Wolfenden, David C.C.; Leach, Matthew C.; Valentim, Ana M.; Steenbergen, Peter J.; Bardine, Nabila; Currie, Amanda D.; Broom, Donald M.; and Brown, Culum (2018) Fish sentience denial: Muddying the waters. Animal Sentience 21(1)

DOI: $10.51291 / 2377-7478.1317$

Date of submission: 2018-03-21

Date of acceptance: 2018-05-02

(c) $\mathrm{G}$




\section{Sneddon, Lynne U.; Lopez-Luna, Javier; Wolfenden, David C.C.; Leach, Matthew C.;}

Valentim, Ana M.; Steenbergen, Peter J.; Bardine, Nabila; Currie, Amanda D.;

Broom, Donald M.; and Brown, Culum (2018) Fish sentience denial: Muddying the waters. Animal Sentience 21(1)

DOI: $10.51291 / 2377-7478.1317$

Date of submission: 2018-03-21

Date of acceptance: 2018-05-02

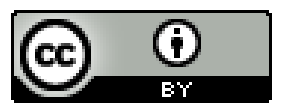

Authors

Lynne U. Sneddon, Javier Lopez-Luna, David C.C. Wolfenden, Matthew C. Leach, Ana M. Valentim, Peter J. Steenbergen, Nabila Bardine, Amanda D. Currie, Donald M. Broom, and Culum Brown 
Call for Commentary: Animal Sentience publishes Open Peer Commentary on all accepted target articles. Target articles are peer-reviewed. Commentaries are editorially reviewed. There are submitted commentaries as well as invited commentaries. Commentaries appear as soon as they have been reviewed, revised and accepted. Target article authors may respond to their commentaries individually or in a joint response to multiple commentaries.

Instructions: animalstudiesrepository.org/animsent/guidelines.html

\title{
Fish sentience denial: Muddying the waters
}

\section{Lynne U. Sneddon ${ }^{1}$, Javier Lopez-Luna ${ }^{1}$, David C.C. Wolfenden ${ }^{2}$, Matthew C. Leach ${ }^{3}$, Ana M. Valentim ${ }^{4}$, Peter J. Steenbergen ${ }^{5}$, Nabila Bardine ${ }^{6}$, Amanda D. Currie ${ }^{7}$, Donald M. Broom ${ }^{8}$ \& Culum Brown ${ }^{9}$}

\author{
${ }^{1}$ Institute of Integrative Biology, University of Liverpool, Liverpool, UK \\ ${ }^{2}$ Blue Planet Aquarium, Cheshire Oaks, Cheshire, UK \\ ${ }^{3}$ School of Natural and Environmental Sciences, Newcastle University, Newcastle upon Tyne, UK \\ ${ }^{4}$ Institute of Molecular and Cell Biology, University of Porto, Porto, Portugal \\ ${ }^{5}$ Developmental Biology Unit, European Molecular Biology Laboratory Heidelberg, Germany \\ ${ }^{6}$ Holistic Life Coach, Heidelberg, Germany \\ ${ }^{7}$ Department of Psychology, Macalester College, Saint Paul, MN \\ 8Department of Veterinary Medicine, University of Cambridge, UK \\ ${ }^{9}$ Department of Biological Sciences, Macquarie University, NSW, Australia
}

\begin{abstract}
Recent empirical studies have reported evidence that many aquatic species, including fish, cephalopods and crustaceans, have the capacity for nociception and pain, and that their welfare should be taken into consideration. Some sceptics, rejecting the precautionary principle, have denied that any study demonstrates pain or other aspects of sentience in fish. This target article discusses some of the scientific shortcomings of these critiques through a detailed analysis of a study exploring nociception and analgesia in larval zebrafish.
\end{abstract}




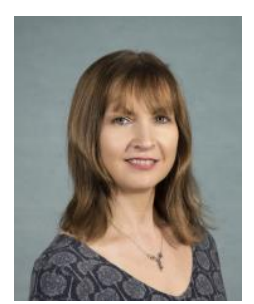

Lynne U. Sneddon, Director, Bioveterinary Science, University of Liverpool, was one o the first to discover nociceptors that detect painful stimuli in fish. Her empirical studies drive the fish welfare agenda in many contexts.

www.liv.ac.uk/integrative-

biology/stafæf/lynne-sneddon/

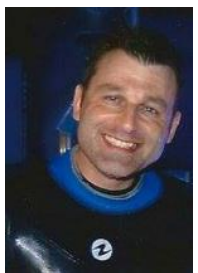

David C.C. Wolfenden, M. Phil in ornamental fish welfare, is Curator at Blue Planet Aquarium, UK, where he is engaged in aquatic animal conservation and welfare research.

www.pressreader.com/uk/practical-

fishkeeping-

uk/20170901/281595240598414

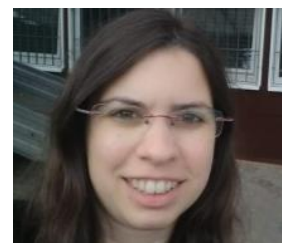

Ana M. Valentim, postdoctoral researcher, Instituto de Investigação e Inovação em Saúde, University of Porto, assesses anaesthesia in rodents and zebrafish. www.i3s.up.pt/content/people?id=34\& idg $=29$

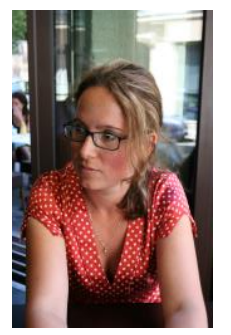

Nabila Bardine developmental biologist interested in animal behaviour and welfare helps humans lower their stress levels and improve their wellbeing through holistic therapy.

www.researchgate.net/profile/Nabila Bardine

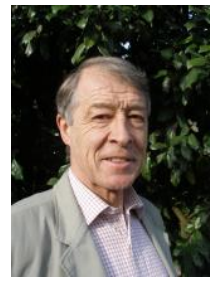

Donald M. Broom, Emeritus Professor of Animal Welfare, Department of Veterinary Medicine, Cambridge University, has worked on sentience, sustainability and the welfare of a wide range of animals including fish.

www.neuroscience.cam.ac.uk/director y/profile.php?dmb16

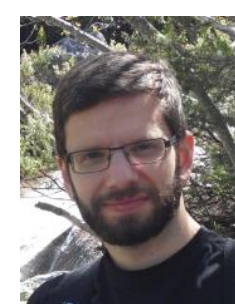

Javier Lopez-Luna, postdoctoral researcher, specialises in fish welfare, behaviour and biology. His work aims at understanding the behavioural and physiological effects of pain and stress in different species including trout and zebrafish.

www.liverpool.ac.uk/integrative-

biology/staff/evolution-ecology-and-

behaviour/

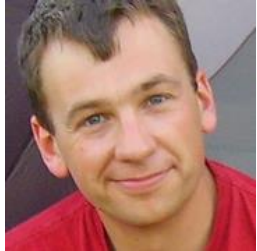

Matthew C. Leach, Newcastle University Pain \& Animal Welfare Science Group, works on assessing and alleviating pain in mammals. Leach gauges pain noninvasively through the use of grimace scales. www.ncl.ac.uk/cbe/about/staff/profile/matthe wleach.html\#background

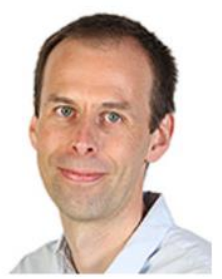

Peter I. Steenbergen helped develop behavioural tests to assess stress and fear in larval zebrafish and described the ability of buprenorphine to alleviate their response to noxious chemicals and electrical stimuli.

www.embl.de/research/units/dev biology/ikmi/me mbers/index.php?s personId=CP-60027661

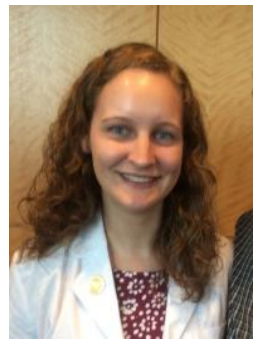

Amanda D. Currie studied neuroscience at Macalester College in St. Paul, Minnesota, where she focused on developing a model of pain in zebrafish. She is now a student in the College of Medicine at the University of Tennessee Health Science Center and plans to specialize in neurology.

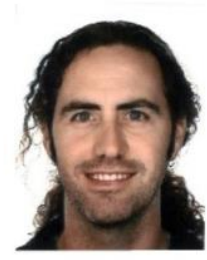

Culum Brown studies behavioural ecology of fishes with a special interest in cognition, personality and laterality. He is Associate Professor of vertebrate evolution at Macquarie University, Co-Editor of the volume Fish Cognition and Behavior, and Editor of the Journal of Fish Biology. thefishlab.com 
Recent advances in our understanding of the complexity of their behaviour, physiology and neurobiology have suggested that fish and other aquatic species are far from being just reflexive automata. Indeed, they meet Broom's (2014, 2016a) criteria for sentience, including the ability to experience positive and negative emotions.

According to Broom's definition, sentience includes some degree of awareness. This may seem challenging to demonstrate in non-human animals, but many studies of behaviour and cognition have reported evidence of perceptual, cognitive and higher-order awareness. Gerlach et al. (2008) have reported kin recognition in early larvae. Thunken et al. (2009) have shown that fish can distinguish their own odour from that of others and can hence recognise themselves. Manta rays perform self-directed behaviours in mirror selfrecognition tests (Ari \& D'Agostino 2016), an ability considered indicative of awareness in mammals and other groups of animals (Sommerville and Broom 1998; Broom 2014). For various animals, sentience, and hence the ability to suffer, is denied by some because sentience is at the heart of the decision about whether to provide animals with legislative protection.

Broom (2014) discusses some of the prejudices about sentience. Among these is the idea that despite sharing many aspects of brain and other biological functions, humans are different from all other animals, and that mammalian brain function is superior despite the fact that some brain functions of fish are just as good as those of mammals or even better. Some authors even feel the need to refer to "humans and animals," as if humans were not themselves animals. In some countries this speciesism has led to obstacles and scepticism when it comes to the protection of aquatic animals in particular (e.g., Stevens et al. 2016; Diggles et al. 2017; Key et al. 2017).

The protection afforded to mammals fails to be applied to fish for many reasons, including the sense of phylogenetic distance of humans from fish, lack of knowledge regarding the welfare of fish, and the greater emotional attachment of humans to other mammals compared to fish (Ormandy \& Schuppli 2014). Fish are more diverse than mammals. Complex processing linked to specialisation of the senses in fish brains occurs in different regions in different fish groups (Kotrschal et al. 1998). This diversity has resulted in legislation containing fewer details about the care of aquatic animals other than mammals (EU directive 2010/63).

Evolution of brain function in mammals took the form of a shift of many processes to the multi-layered cerebral cortex in contrast to the singly laminated cortex of birds and fish, thus complicating direct comparisons between taxa regarding functional anatomy. All modern fish have sophisticated learning abilities, however. Bshary et al. (2002) found that almost all abilities reported for primates can also be found in fish, with homologous or analogous brain function in nearly all cases (Broglio et al. 2011).

Bony fish (Osteichthyes) split into two classes early in evolution producing the Sarcopterygii (lobefinned fishes) and the Actinopterygii (ray-finned fishes). The lobe-finned fish class led to the evolution of the tetrapods. So, it is not surprising that the sensory-processing regions, including those for pain, in mammals are not identical to those in all fish (Broom 2014), although their evolutionary origins may be found in fish. Studies have shown molecular, electrophysiological and in vivo activity changes in the fish forebrain and midbrain regions during painful stimulation that differ from the response to innocuous stimulation (Sneddon 2015). Processing is not restricted to hindbrain and spinal reflexes as sceptics have suggested (Rose 2002). It is the complexity of brain function that is the scientific issue (Woodruff 2017), not the idea that fish cannot feel pain because they do not have neocortico-thalamic links (Rose 2002).

In some fish, the medial and lateral telencephalic pallium process emotion and learning, as they do in birds (Güntürkün \& Bugnyar 2016; Iwaniuk 2017). Muto et al (2013) demonstrate neuronal activity in the optic tectum of larval zebrafish during active behaviour. Agetsuma et al. (2010) report that in zebrafish, as in mammals, the habenula is critical for fear-dependent learning. Fish do not have an amygdala and hippocampus that is anatomically homologous to those of humans, but they have analogous brain areas whose function is to control and learn from emotional responses (Broom 2016b). We hence cannot expect that the fish brain will process pain in the same way as a mammalian brain, but it is likely to be very similar in function (Woodruff 2017).

Despite the empirical evidence (Sneddon 2015), sceptics still deny anything beyond reflex responses in fishes and state that they are incapable of complex cognitive abilities (Rose 2002; Rose et al. 2014). Recent 
studies (Salwiczek et al. 2012; Pepperberg and Hartsfield 2014) on learning have shown that cleaner wrasse fish as well as parrots perform better than chimpanzees, orangutans or capuchin monkeys in a complex learning task in which they have to learn to discriminate reliable food sources from unreliable ones. Goldfish learn to avoid an area where they have received an electric shock (Dunlop et al. 2006). Even when food has been previously provided in this area and the fish are strongly motivated to spend time there, they avoid it for three days, at which time they trade off their hunger with the risk of receiving another shock (Millsopp \& Laming 2009). This demonstrates complex decision-making beyond simple reflexes.

Whenever there is doubt about an animal ability, such as that fish are sentient, it is prudent to use the precautionary principle. But even widespread calls for use of the precautionary principle (Jones 2016; Birch 2017; Brown 2017) have been called into question by sceptics (e.g., Key 2016). The precautionary principle in this context is that a lack of full scientific certainty should not be used as a reason for postponing measures to prevent the possibility of serious negative animal welfare outcomes (Birch 2017). This approach is widely adopted in environmental (UN 1992) and public health management (John 2011) specifically to deal with scientific uncertainty. When discussing the ethical, moral and welfare implications of fish pain and suffering, the costs are measured by the potential impact on fish welfare that can be calculated using a risk-assessment matrix. The matrix is simply a function of the probability that fish are sentient multiplied by the very large number of animals involved (Brown 2017). Some sceptics have little interest in the animal welfare costs and concentrate instead on the perceived economic costs of possible management actions. Key (2016), for example, suggests that we should abandon the precautionary principle because the costs to industry would be too high. Similar arguments were made against the animal welfare movements of the late 20th century in the context of industrial farming in terrestrial systems.

The arguments of those who are persistently critical of fish welfare findings are based on a failure to understand specific but important points about methodology and about mechanisms in animal function. By way of illustration, we will report some of the critics' comments, especially regarding a study by Lopez-Luna et al. (2017a). This study demonstrated that five days after fertilisation (5dpf), larval zebrafish respond to noxious, potentially painful stimulation (acid) in the same way adult fish do, by decreasing activity. This response was then ameliorated by a range of analgesic or pain-relieving drugs. Diggles et al. (2017) do not contest that adult zebrafish experience pain, but they do criticise the use of $5 \mathrm{dpf}$ larvae to replace adults despite these findings, which demonstrate that the use of larval zebrafish could replace current protocols using adults as recommended by the concept of the 3Rs in the European legislation and in the guidelines for animal care in other countries. Fish larvae are not protected in some countries until they are free-feeding forms, and in the case of zebrafish, this is from $5 \mathrm{dpf}$ onwards (Strähle et al. 2012). However, due to the increasing number of studies regarding nociception in $5 \mathrm{dpf}$ larvae, should the age of protection be lowered? These studies demonstrate that $5 \mathrm{dpf}$ zebrafish respond to a noxious stimulus in the same way as adults, from gene expression to behavioural changes (Curtwright et al. 2015; Lopez-Luna et al. 2017a, b, c, d). Does this mean that they experience pain in the same way adults do or is it only a reflex? The fact that legislation in Europe and other countries only protects larval forms of fish once they are capable of independent feeding does not mean that they do not feel pain before then. Further studies are required to ensure that $5 \mathrm{dpf}$ larvae meet all the criteria for animal pain (Sneddon et al. 2014) before this decision can be taken.

Sneddon et al. (2017) have responded to the critique of the Lopez-Luna et al. (2017a) study by Diggles et al., pointing out their methodological misunderstanding. Lopez-Luna et al. demonstrated that immersion in agents with analgesic properties, that is, $2.5 \mathrm{mg} \mathrm{l}^{-1}$ aspirin, $48 \mathrm{mg} \mathrm{l}^{-1}$ morphine and $5 \mathrm{mg} \mathrm{l}^{-1}$ lidocaine, prevented the reduction in activity after acid exposure, thus providing pain relief. The larval results mirror the adult response to acetic acid (Reilly et al. 2008; Schroeder and Sneddon 2017; Taylor et al. 2017; White et al. 2017). However, Diggles et al. assert that a lack of water chemistry data prevents Lopez-Luna et al. (2017a) from interpreting the results of acid exposure in zebrafish larvae. Sneddon et al. (2017) provide more water quality data to demonstrate that this assertion is incorrect. Water quality parameters were generally in the range of tolerance for this species (Avdesh et al. 2012) during the experiments. In another study under identical 
conditions, heat was used as the noxious stimulus rather than acid, maintaining the water quality (Lopez-Luna et al. 2017b). The outcome of this study, identical to the one they criticised, was not referred to by Diggles et al.

Also raised by Diggles et al. was the very important issue of the reproducibility crisis in science (e.g., McNutt 2014) whereby incomplete reporting of results can lead to disparate findings between laboratories because of unknown water quality parameters. Some authors do not follow these standards; they rarely report water parameters (e.g., Correia et al. 2011; Schroeder et al. 2016; Messmer et al. 2017). Yet in Lopez-Luna et al.'s (2017a) study, data on water quality are provided: $\mathrm{pH}$, osmolarity, ammonia, nitrite and nitrate, all important in fish husbandry; see also Sneddon et al. (2017) for further measurements. Lopez-Luna et al. have published other studies using zebrafish larvae as a model $(2017 \mathrm{~b}, \mathrm{c}, \mathrm{d})$, providing full methodological information, allowing other laboratories to either replicate the methods or assist in explaining any differences in results when these parameters differ. We urge authors to consider the ARRIVE guidelines (NC3Rs 2017), which provide a checklist of key facts to report when publishing empirical studies to allow reproducibility and avoid the unnecessary use of animals and time.

Diggles et al. also suggested that the concentrations of analgesics used by Lopez-Luna et al (2017a) were "high" and that this constituted a major flaw. Except for the highest dose of morphine ( $48 \mathrm{mg} \mathrm{l}^{-1}$ ), all doses were based upon published studies using fish models: aspirin for adult zebrafish (Schroeder and Sneddon 2017); morphine for trout (Sneddon 2003), morphine for goldfish (Newby et al. 2009), lidocaine for adult zebrafish (Schroeder and Sneddon 2017) and doses for veterinary clinical use in mammals (Smith et al. 2004). The higher morphine dose was selected using the published research of Stevens, one of the Diggles et al. co-authors (Newby et al. 2006; 2007; 2008; 2009; Stevens and Balahura 2007), who used at least 40mg/kg morphine via injection. These publications warn of the relatively slow uptake and deposition of morphine, which is affected by temperature and $\mathrm{pH}$. Thus, the dose chosen by Lopez-Luna et al (2017a) was comparable to those used in the studies of Stevens and colleagues. Another independent laboratory has subsequently shown that morphine injected intramuscularly at 2.5 and $5 \mathrm{mg} \mathrm{kg}^{-1}$ in adult zebrafish effectively prevents the reduction in activity associated with acetic acid treatment (Taylor et al. 2017).

Diggles et al. also cite the study of Currie (2014), which they claim contrasts with the findings of LopezLuna et al. (2017a). They appear to have misinterpreted the findings of this study, as they state that in Currie's study, activity increased in adult zebrafish exposed to acetic acid, whereas, Currie only measured and statistically analysed the incidence of top-dwelling behaviour by adult zebrafish in a beaker. To quote Currie: "top-dwelling behavior was the most commonly-observed response to $0.03 \%$ acetic acid." Hence, contrary to the suggestion of Diggles et al., only an increase in top-dwelling behaviour was observed; general activity was not quantified.

Diggles et al. criticise a comparable study by Steenbergen and Bardine (2014), stating that the behavioural outcomes contradicted those of the Lopez-Luna et al. (2017a) study. Steenbergen and Bardine showed that lower concentrations of acetic acid $(0.0025,0.005,0.01$, and $0.025 \%)$ increased larval activity, instead of decreasing it as in Lopez-Luna et al. However, Lopez-Luna et al. demonstrate that $0.1 \%$ acetic acid is the minimum effective threshold dose to induce a decline in activity in larval zebrafish. Steenbergen and Bardine only exposed larvae to $0.0025 \%$ to $0.025 \%$ acetic acid, which is sub-threshold. In both studies, however, $0.01 \%$ exposure to acetic acid increased larval activity, contradicting the assumption of Diggles et al. that the two studies disagreed. Moreover, Steenbergen and Bardine mention in their discussion that they exposed larvae to higher concentrations of acetic acid, $1 \%$ to $5 \%$, which decreased larval locomotor activity. These concentrations were not used in the main study of the paper because they were too high and led to death.

Steenbergen and Bardine showed that larvae treated with "buprenorphine, a post-operative morphinelike analgesic used in mammals and humans," did not change locomotor activity in response to acid. When naloxone (a morphine antagonist) was used as a pre-treatment prior to the addition of buprenorphine, the larvae exhibited an increase in locomotor activity upon acetic acid treatment, clearly demonstrating the involvement of the opioid pathway in this response. This demonstrates that this pathway is activated upon acetic acid treatment in larvae as young as $5 \mathrm{dpf}$. The opioid family includes the drugs that are most effective clinically for producing temporary analgesia and relief from pain (Dafny 1997). The evolutionary conservation of nociceptive 
pathways in zebrafish is further evidence that these animals, like mammals, use these conserved genes and proteins for nociception (Echteler and Saidel 1981; Stevens 2009). Diggles et al. also suggest that the use of Cox2 is flawed in Steenbergen and Bardine, as they consider it a non-specific marker of several physiological processes. This enzyme is indeed expressed at sites of inflammation, infection, and cancer (Morita 2002; Kirby 2016). However, a very large amount of data and many peer-reviewed articles have shown that Cox-2 expression is also a useful indicator strongly linked to pain and nociception in zebrafish (Grosser et al. 2002) as well as in other vertebrates, including humans (Chen et al. 2012; Ebersberger et al. 1999; Samad et al. 2001; Katz 2002; Lee et al. 2005; Sinatra 2002). Steenbergen and Bardine recognize that the locomotor activity may be influenced by "anxiety, handling stress, hyper arousal or altered sensitivity of side-line receptors." The handling stress, however, is the same for all the groups; and buprenorphine and its antagonist induced the expected animal behaviour when an opioid pathway was active. The behavioural change in response to acid is supported by the increased expression of Cox-2. Together, these results are all evidence of nociception.

Regarding the substance administration by immersion of larvae, Diggles et al. suggest that anaesthetising individual adult fish and injecting them with chemicals is a better approach. However, this contradicts what these authors previously said about injecting adult fish, stating that the requirement to use anaesthesia can be a confounding factor and that these studies using adult fish have a low sample size, even though they generate statistically significant results that have been subject to rigorous peer review (Rose et al. 2014).

Finally, Diggles et al. use quotation marks that appear to suggest that statements were taken from LopezLuna et al. (2017a) when this was not the case, as we cannot find the terms "alleged pain behaviour" in this publication. Lopez-Luna et al. demonstrated quite clearly that larval zebrafish show behavioural responses (reduced activity) similar to those of adult zebrafish in the acetic acid test which are reversed by a range of drugs with documented analgesic or local anaesthetic properties. This demonstrates that the behavioural changes in response to noxious stimuli are modulated by nociceptive mechanisms: lidocaine, aspirin and morphine block the nociceptive system via different routes (Sneddon 2012), other than olfactory ones. Thus, there is compelling evidence that $5 \mathrm{dpf}$ zebrafish larvae are indeed a useful replacement for adult fish and that these can be assessed in a high-throughput manner with several larvae in a well plate analysed once rather than one adult per tank. Indeed, another independent laboratory has demonstrated that larval zebrafish exhibit thermal nociception; this avoidance of noxious heat was sensitised by the inflammatory compound and TRPA 1 agonist allyl isothiocyanate (Curtwright et al. 2015). This study used formalin as a noxious stimulus. It induces a similar decrease in larvae activity, which is reversed by the use of morphine and indomethacin, an opioid and an NSAID, respectively (Magalhaes et al. 2017). These studies demonstrate the utility of zebrafish larvae in studies of nociception and analgesia.

Diggles et al. have previously criticised aquatic animal welfare studies (see: Stevens et al. 2016; Key et al. 2017). Each critique has been answered with robust and scientifically sound rebuttals by the authors of the criticised papers (Elwood 2016; Rey et al. 2017) as well as by others (e.g., Broom 2016b) who point out fallacies that are implicit in the arguments of Diggles et al., Stevens et al. (2016), and Key et al. (2017). In the case of Elwood (2016), Stevens et al. (2016) claim that the study they were criticizing stated that stress was the same as pain. Elwood points out that Stevens et al. (2016) make a misleading statement: what was said was that the physiological stress response associated with noxious stimuli is one of the expected criteria for animal pain and that this criterion has been met by the European shore crab (Elwood \& Adams 2015). In another case, Key et al. (2017) claim the statement that the expression of emotional fever in zebrafish proves that fish are conscious is flawed. Rey et al. (2017) stated only that their zebrafish exhibited emotional fever; hence the absence of emotional fever in fish can no longer be cited in support of the absence of consciousness in fish.

The discussion of opposing opinions, when logical and well-formulated, is vital and helps progress in science. That is why we are happy to submit this persistent peer disagreement to open peer commentary in this journal. One important point on which we are in complete agreement with Diggles et al. (2017), however, is that more funding is needed in the area of fish welfare to provide robust empirical evidence we can use to inform the humane and ethical treatment of fish. 
Competing interests: The authors declare no competing interests.

Funding: The authors were not funded to write this response.

\section{References}

Agetsuma, M., Aizawa, H., Aoki, T., Nakayama, R., Takahoko, M., Goto, M., Sassa, T., Kawakami, K. and Okamoto, H. (2010). The habenula is crucial for experience-dependent modification of fear responses in zebrafish. Nature Neuroscience 13, 1354-1356.

Altundoğan, H. S., Topdemir, A., Çakmak, M. and Bahar, N. (2016). Hardness removal from waters by using citric acid modified pine cone. Journal of the Taiwan Institute of Chemical Engineers 58, 219-225.

Ari, C. and D'Agostino, D. P. (2016). Contingency checking and self-directed behaviors in giant manta rays: Do elasmobranchs have self-awareness? Journal of Ethology 34, 167-174.

Ashley. P. J., Sneddon, L. U. and McCrohan, C. R. (2006). Properties of corneal receptors in a teleost fish. Neuroscience Letters 410, 165-168.

Ashley, P. J., Sneddon, L. U. and McCrohan, C. R. (2007). Nociception in fish: stimulus-response properties of receptors on the head of trout Oncorhynchus mykiss. Brain Research 1166, 47-54.

Avdesh, A., Chen, M., Martin-Iverson, M. T., Mondal, L., Ong, D., Rainey-Smith, S., Taddei, K. Lardelli, M., Groth, D. M., Verdile, G. and Martins, R. N. (2012). Regular care and maintenance of a zebrafish (Danio rerio) laboratory: An introduction. Journal of Visualized Experiments 69, e4196.

Birch, J. (2017). Animal sentience and the precautionary principle. Animal Sentience 16(1).

Brand, M., Granato, M. and Nüsslein-Volhard, C. (2002). Keeping and raising zebrafish. In Nüsslein-Volhard, C. and Dahm, R. (Eds.), Zebrafish: A Practical Approach. Oxford University Press, Oxford, pp. 7-37.

Broglio, C., Gomez, A., Duran, E., Salas C. and Rodriguez, F. (2011). Brain and cognition in teleost fishes. In Brown, C., Laland, K., Krause, J. (Eds.), Fish Cognition and Behaviour. Wiley-Blackwell, pp. 325-358.

Broom, D. M. (2014). Sentience and Animal Welfare (pp. 200). Wallingford: CABI.

Broom, D. M. (2016a). Considering animals' feelings: Précis of Sentience and animal welfare (Broom 2014). Animal Sentience 5(1).

Broom, D. M. (2016b). Fish brains and behaviour indicate capacity for feeling pain. Animal Sentience 3(4).

Brown, C. (2017). A risk assessment and phylogenetic approach. Animal Sentience 16(3).

Bshary, R., Wickler, W. and Fricke, H. (2002). Fish cognition, a primate's eye view. Animal Cognition 5, 1-13.

Chen, J. J., Hung, K. C., Lu, K., Yu, S. W., Chang, C. C., Liu, C. C., Spielberger, J., Ku, P. Y. and Tan, P. H. (2012). The pre-emptive analgesic effect of a cyclooxygenase- 2 inhibitor in a rat model of acute postoperative pain. Anaesthesia 67, 1225-1231.

Correia, A. D., Cunha, S. R., Scholze, M. and Stevens, E. D. (2011). A novel behavioral fish model of nociception for testing analgesics. Pharmaceuticals 4, 665-680.

Currie, A. D. (2014). Toward a novel model of pain in zebrafish: Exposure to water containing dilute concentrations of acetic acid. Psychology Honors Projects. Paper 33.

Curtright, A., Rosser, M., Goh, S., Keown, B., Wagner, E., Sharifi, J., Raible, D. W. and Dhaka, A. (2015). Modeling nociception in zebrafish: A way forward for unbiased analgesic discovery. PLoS One 10, e0116766.

Dafny, N. (1997). Pain modulation and mechanisms. In Byrne, J. H. and Dafny, N. (Eds.), Neuroscience Online: An Electronic Textbook for the Neurosciences.

Diggles, B. K., Arlinghaus, R., Browman, H. I., Cooke, S. J., Cowx, I. G., Kasumyan, A. O., Key, B., Rose, J. D., Sawynok, W., Schwab, A., Skiftesvik, A. B., Stevens, E. D., Watson, C. A. and Wynne, C. D. L. (2017). Responses of larval zebrafish to low $\mathrm{pH}$ immersion assay. Comment on Lopez-Luna et al. Journal of Experimental Biology 220, 3191-3192.

Dunlop, R., Millsopp, S. and Laming, P. (2006). Avoidance learning in goldfish (Carassius auratus) and trout (Oncorhunchus mykiss) and implications for pain perception. Applied Animal and Behaviour Science 97, 255271. 
Ebersberger, A., Grubb, B. D., Willingale, H. L., Gardiner, N. J., Nebe, J. and Schaible, H. G. (1999). The intraspinal release of prostaglandin E2 in a model of acute arthritis is accompanied by an up-regulation of cyclooxygenase-2 in the spinal cord. Neuroscience 93, 775-781.

Echteler, S. M. and Saidel, W. M. (1981). Forebrain connections in the goldfish support telencephalic homologies with land vertebrates. Science 212, 683-685.

Elwood, R. W. (2016). Stress was never said to be pain: Response to Stevens et al. (2016). Biology Letters 12, 20160126.

Elwood R. W. and Adams, L. (2015). Electric shock causes physiological stress responses in shore crabs, consistent with prediction of pain. Biology Letters 11, 20150800.

Gerlach, G., Hodgins Davis, A., Avolio, C. and Schunter, C. (2008). Kin recognition in zebrafish: A 24 hour window for olfactory imprinting. Proceedings of the Royal Society B 275, 0647.

Green, B. G. (2004). Temperature perception and nociception. Journal of Neurology 61, 13-29.

Grosser, T., Yusuff, S., Cheskis, E., Pack, M. A. and FitzGerald, G. A. (2002). Developmental expression of functional cyclooxygenases in zebrafish. Proceedings of the National Academy of Science U.S.A. 99, 84188423.

Güntürkün, O. and Bugnyar, T. (2016). Cognition without cortex. Trends in Cognitive Sciences 20(4), 291-303.

Hamamoto, D. T. and Simone, D. A. (2003). Characterization of cutaneous primary afferent fibers excited by aceticacid in a model of nociception in frogs. Journal of Neurophysiology 90, 566-577.

Issberner, U., Reeh, P. W. and Steen, K. H. (1996). Pain due to tissue acidosis: A mechanism for inflammatory and ischemic myalgia? Neuroscience Letters 208, 191-194.

Iwaniuk, A. N. (2017). The evolution of cognitive brains in non-mammals. In Evolution of the Brain, Cognition, and Emotion in Vertebrates (pp. 101-124). Springer, Tokyo.

John, S. (2011). Risk and precaution. In Dawson, A. (Ed.), Public Health Ethics: Key Concepts and Issues in Policy and Practice, pp. 67-84

Jones, R. C. (2016). Fish sentience and the precautionary principle. Animal Sentience 3(10).

Katz, W. A. (2002). Cyclooxygenase-2-selective inhibitors in the management of acute and perioperative pain. Cleveland Clinic Journal of Medicine 69(Suppl. 1), S165-S175.

Keele, C. A. and Armstrong, D. (1964). Pain due to acids and alkalis. In Keele, C. A. and Armstrong, D. (Eds.), Substances Producing Pain and Itch. Baltimore, MD: Williams and Wilkins, pp. 73-88.

Key, B., Arlinghaus, R., Browman, H. I., Cooke, S. J., Cowx, I. G., Diggles, B. K., Rose, J. D., Sawynok, W., Schwab, A., Skiftesvik, A. B., Stevens, E. D. and Watson, C. A. (2017). Problems with equating thermal preference with 'emotional fever' and sentience: Comment on 'Fish can show emotional fever: Stress-induced hyperthermia in zebrafish' by Rey et al. (2015). Proceedings of the Royal Society of London B 284, 20160681.

Kirkby, N. S., Chan, M. V., Zaiss, A. K., Garcia Vaz, E., Jiao, J., Berglund, L., Verdu, E. F., Ahmetaj-Shala, B., Wallace, J. L., Herschman, H. R., Gomez, M. and Mitchell, J. A. (2016). Systematic study of constitutive cyclooxygenase-2 expression: Role of NF- $\mathrm{KB}$ and NFAT transcriptional pathways. Proceedings of the National Academy of Sciences 113(2), 434-439.

Klement, W. and Arndt, J. O. (1991). Pain on iv injection of some anaesthetic agents is evoked by the unphysiological osmolality or pH of their formulations. British Journal of Anaesthesia 66, 189-195.

Kotrschal, K., Van Staaden, M.J. and Huber, R. (1998). Fish brains: Evolution and environmental relationships. Reviews in Fish Biology and Fisheries 8, 373-408.

Kramer, D. L. (1987). Dissolved oxygen and fish behavior. Environmental Biology of Fishes 18, 81-92.

Lawrence, C. (2009). The husbandry of zebrafish (Danio rerio): A review. Aquaculture 269, 1-20.

Lee, Y., Rodriguez, C. and Dionne, R. A. (2005). The role of COX-2 in acute pain and the use of selective COX-2 inhibitors for acute pain relief. Current Pharmaceutical Design 11, 1737-1755.

Lindahl, O. (1961). Experimental skin pain: Induced by injection of water-soluble substances in humans. Acta Physiologica Scandanavica 51(Suppl. 179), 1-89. 
Lopez-Luna, J., Al-Jubouri, Q., Al-Nuaimy, W. and Sneddon, L. U. (2017a). Activity reduced by noxious chemical stimulation is ameliorated by immersion in analgesic drugs in zebrafish. Journal of Experimental Biology 220, 1451-1458.

Lopez-Luna, J., Al-Jubouri, Q., Al-Nuaimy, W. and Sneddon, L. U. (2017b). Impact of analgesic drugs on the behavioural responses of larval zebrafish to potentially noxious temperatures. Applied Animal Behaviour Science 188, 97-105.

Lopez-Luna, J., Al-Jubouri, Q., Al-Nuaimy, W. and Sneddon, L. U. (2017c). Impact of stress, fear and anxiety on the nociceptive responses of larval zebrafish. PLoS One 12(8), e0181010.

Lopez-Luna, J., Canty, M. N., Al-Jubouri, Q., Al-Nuaimy, W. and Sneddon, L. U. (2017d). Behavioural responses of fish larvae modulated by analgesic drugs after a stress exposure. Applied Animal Behaviour Science 195, 115-120.

Magalhaes, F. E. A., de Sousa, C. A. P. B., Santos, S. A. A. R., Menezes, R. B., Batista, F. L. A., Abreu, Â. O., de Oliveira, M. V., Moura, L. F. W. G., Raposo, R. S. and Campos, A. R. (2017). Adult zebrafish (Danio rerio): An alternative behavioral model of Formalin-induced nociception. Zebrafish 14, 422-429.

McNutt, M. (2014). Journals unite for reproducibility. Science 346, 679.

Messmer, V., Pratchett, M. S., Hoey, A. S., Tobin, A. J., Coker, D. J., Cooke, S. J. and Clark, T. D. (2017). Global warming may disproportionately affect larger adults in a predatory coral reef fish. Global Change Biology 23, 2230-2240.

Mettam J. J., McCrohan C. R. and Sneddon, L. U. (2012). Characterisation of chemosensory trigeminal receptors in the rainbow trout (Oncorhynchus mykiss): Responses to irritants and carbon dioxide. Journal of Experimental Biology 215, 685-693.

Millsopp, S. and Laming, P. (2008). Trade-offs between feeding and shock avoidance in goldfish (Carassius auratus). Applied Animal Behaviour Science 113, 247-254.

Morita, I. (2002). Distinct functions of COX-1 and COX-2. Prostaglandins \& Other Lipid Mediators 68-69, 165175.

Muto, A., Ohkura, M., Abe, G., Nakai, J. and Kawakami, K. (2013). Real-time visualization of neuronal activity during perception. Current Biology 23, 307-311.

NC3Rs. (2017). ARRIVE guidelines.

Newby, N. C., Gamperl, A. K. and Stevens, E. D. (2007). Cardiorespiratory effects and efficacy of morphine sulfate in winter flounder (Pseudopleuronectes americanus). American Journal of Veterinary Research 68, 592-597.

Newby, N. C., Mendonca, P. C., Gamperl, K. and Stevens, E. D. (2006). Pharmacokinetics of morphine in fish: Winter flounder (Pseudopleuronectes americanus) and seawater-acclimated rainbow trout (Oncorhynchus mykiss). Comparative Biochemistry and Physiology C 143, 275-283.

Newby, N. C., Robinson, J. W., Vachon, P., Beaudry, F. and Stevens, E. D. (2008). Pharmacokinetics of morphine and its metabolites in freshwater rainbow trout (Oncorhynchus mykiss). Journal of Veterinary Pharmacology and Therapeutics 31, 117-127.

Newby, N. C., Wilkie, M. P. and Stevens, E. D. (2009). Morphine uptake, disposition, and analgesic efficacy in the common goldfish (Carassius auratus). Canadian Journal of Zoology 87, 388-399.

Ormandy, E. H. and Schuppli, C. A. (2014). Public attitudes toward animal research: A review. Animals 4(3), 391-408.

Pepperberg, I. M. and Hartsfield, L. A. (2014). Can grey parrots (Psittacus erithacus) succeed on a "complex" foraging task failed by nonhuman primates (Pan troglodytes, Pongo abelii, Sapajus apella) but solved by wrasse fish (Labroides dimidiatus)? Journal of Comparative Psychology 128, 298.

Reilly, S. C., Quinn, J. P., Cossins, A. R. and Sneddon, L. U. (2008). Behavioural analysis of a nociceptive event in fish: Comparisons between three species demonstrate specific responses. Applied Animal Behaviour Science $114,248-259$.

Rey, S., Huntingford, F. A., Knowles, T. G. and Mackenzie, S. (2017). Stress induced hyperthermia in zebrafish: A reply to Key et al. Proceedings of the Royal Society of London B 284, 106.2124. 
Rose, J. D. (2002). The neurobehavioral nature of fishes and the question of awareness and pain. Reviews in Fisheries Science 10, 1-38.

Rose, J. D., Arlinghaus, R., Cooke, S. J., Diggles, B. K., Sawynok, W., Stevens, E. D. and Wynne, C. D. L. (2014). Can fish really feel pain? Fish and Fisheries 15, 97-133.

Salwiczek L. H., Prétôt, L., Demarta L., Proctor, D., Essler, J., Pinto A. I., Wismer, S., Stoinski, T., Brosnan, S. F. and Bshary, R. (2012). Adult cleaner wrasse outperform capuchin monkeys, chimpanzees and orang-utans in a complex foraging task derived from cleaner-client reef fish cooperation. PLoS ONE 7, e49068.

Samad, T. A., Moore, K. A., Sapirstein, A., Billet, S., Allchorne, A., Poole, S., Bonventrek, J. V. and Woolf, C. J. (2001). Interleukin-1b-mediated induction of Cox-2 in the CNS contributes to inflammatory pain hypersensitivity. Nature 410, 471-475.

Schroeder, A., Kalinkat, G. and Arlinghaus, R. (2016). Individual variation in functional response parameters is explained by body size but not by behavioural types in a poeciliid fish. Oecologia 182, 1129-1140.

Schroeder, P. and Sneddon, L. U. (2017). Exploring the efficacy of immersion analgesics in zebrafish using an integrative approach. Applied Animal Behaviour Science 187, 93-102.

Sinatra, R. (2002). Role of COX-2 inhibitors in the evolution of acute pain management. Journal of Pain \& Symptom Management 24(1S), S18-S27.

Smith, L. J., Bentley, E., Shih, A. and Miller, P. E. (2004). Systemic lidocaine infusion as an analgesic for intraocular surgery in dogs: A pilot study. Veterinary Anaesthesia and Analgesia 31, 53-63.

Sneddon, L. U. (2002). Anatomical and electrophysiological analysis of the trigeminal nerve in a teleost fish, Oncorhynchus mykiss. Neuroscience Letters 319, 167-171.

Sneddon, L. U. (2003). Trigeminal somatosensory innervation of the head of a teleost fish with particular reference to nociception. Brain Research 972, 44-52.

Sneddon, L. U. (2012). Clinical anaesthesia and analgesia in fish. Journal of Exotic Pet Medicine 21, 32-43

Sneddon, L. U., Braithwaite, V. A. and Gentle, M. J. (2003a). Do fishes have nociceptors? Evidence for the evolution of a vertebrate sensory system. Proceedings of the Royal Society of London B 270,1115-1121.

Sneddon, L. U., Braithwaite, V. A. and Gentle, M. J. (2003b). Novel object test: Examining nociception and fear in the rainbow trout. The Journal of Pain, 4, 431-440.

Sneddon, L. U., Lopez-Luna, J., Wolfenden, D. C. C., Leach, M. C., Valentim, A. M., Steenbergen, P. J., Bardine, N., Currie, A. D., Broom, D. M. and Brown, C. (2017). Response to: Responses of larval zebrafish to low pH immersion assay. Comment on Lopez-Luna et al. Journal of Experimental Biology 220, 3192-3194.

Sommerville, B. A. and Broom, D. M. (1998). Olfactory awareness. Applied Animal Behaviour Science 57, 269286.

Steenbergen, P. J. and Bardine, N. (2014). Antinociceptive effects of buprenorphine in zebrafish larvae: An alternative for rodent models to study pain and nociception? Applied Animal Behaviour Science 152, 92-99.

Stevens, C. W. (1992). Alternatives to the use of mammals for pain research. Life Sciences 50, 901-912.

Stevens, C. W. (2009). The evolution of vertebrate opioid receptors. Frontiers in Bioscience 14, 1247-1269.

Stevens, C. W. and Willenbring, S. (1997). Pain sensation and analgesia. In Ackerman, L. (Ed.), The Biology, Husbandry and Health Care of Reptiles. Neptune City, NJ: THF Publications, pp. 309-324.

Stevens, C. W., Klopp, A. J. and Facello, J. A. (1994). Analgesic potency of mu and kappa opioids after systemic administration in amphibians. Journal of Pharmacology and Experimental Therapeutics 269, 1086-1093.

Stevens, E. D. and Balahura, R. J. (2007). Aspects of morphine chemistry important to persons working with cold-blooded animals, especially fish. Comparative Medicine 57, 161-166.

Stevens, E. D., Arlinghaus, R., Browman, H. I., Cooke, S. J., Cowx, I. G., Diggles, B. K., Key, B., Rose, J. D., Sawynok, W., Schwab, A., Skiftesvik, A. B., Watson, C. A. and Wynne, C. D. L. (2016). Stress is not pain. Comment on Elwood and Adams (2015) Electric shock causes physiological stress responses in shore crabs, consistent with prediction of pain. Biology Letters 12, 20151006.

Strahle, U., Scholz, S., Geisler, R., Greiner, P., Hollert, H., Rastegar, S., Schumacher, A., Selderslaghs, I., Weiss, C., Witters, H. and Braunbeck, T. (2012). Zebrafish embryos as an alternative to animal experiments-a 
commentary on the definition of the onset of protected life stages in animal welfare regulations. Reproductive Toxicology 33, 128-132.

Taylor, J. C., Dewberry, L. S., Totsch, S. K., Yessick, L. R., DeBerry, J. J., Watts, S. A. and Sorge, R. E. (2017). A novel zebrafish-based model of nociception. Physiology \& Behavior 174, 83-88.

Thunken, T., Waltschyk, N., Bakker, T. C. M. and Kullmann, H. (2009). Olfactory self-recognition in a cichlid fish. Animal Cognition 12, 717-724.

UN. (1992). The Rio declaration on environment and development.

Verhoff, F. H. and Bauweleers, H. (2014). Citric acid. Ullmann's Encyclopedia of Industrial Chemistry. pp. 1-11.

WebMD. (2017). Drug side effects explained.

White, L. J., Thomson, J. S., Pounder, K. C., Coleman R. C. and Sneddon, L. U. (2017). The impact of social context on behaviour and the recovery from welfare challenges in zebrafish, Danio rerio. Animal Behaviour 132, 189-199.

Wood, C. M. (1989). The physiological problems of fish in acid waters. In Morris, R., Taylor, E. W., Brown, D. J. and Brown, J. A. (Eds.), Acid Toxicity and Aquatic Animals. Society for Experimental Biology Seminar Series 34. Cambridge University Press, pp. 125-152.

Woodruff, M. L. (2017). Consciousness in teleosts: There is something it feels like to be a fish. Animal Sentience 13(1).

Call for Commentary: Animal Sentience publishes Open Peer Commentary on all accepted target articles. Target articles are peer-reviewed. Commentaries are editorially reviewed. There are submitted commentaries as well as invited commentaries. Commentaries appear as soon as they have been reviewed, revised and accepted. Target article authors may respond to their commentaries individually or in a joint response to multiple commentaries.

Instructions: animalstudiesrepository.org/animsent/guidelines.html 
UQÀM/ISC Cognitive Science Summer School June 26 - July 6, 2018, Montreal, Canada

\section{The Other Minds Problem: Animal Sentience and Cognition}

Overview: Since Descartes, philosophers know there is no way to know for sure what — or whether - others feel (not even if they tell you). Science, however, is not about certainty but about probability and evidence. The 7.5 billion individual members of the human species can tell us what they are feeling. But there are 9 million other species on the planet (20 quintillion individuals), from elephants to jellyfish, with which humans share biological and cognitive ancestry, but not one other species can speak: Which of them can feel — and what do they feel? Their human spokespersons - the comparative psychologists, ethologists, evolutionists, and cognitive neurobiologists who are the world's leading experts in "mind-reading" other species -- will provide a sweeping panorama of what it feels like to be an elephant, ape, whale, cow, pig, dog, chicken, bat, fish, lizard, lobster, snail: This growing body of facts about nonhuman sentience has profound implications not only for our understanding of human cognition, but for our treatment of other sentient species.

Gregory Berns: Decoding the Dog's Mind with Awake Neuroimaging

Gordon Burghardt: Probing the Umwelt of Reptiles Jon Sakata: Audience Effects on Communication Signals PANEL: Reptiles, Birds and Mammals

WORKSHOP: Kristin Andrews: The "Other" Problems:

Mind, Behavior, and Agency

Sarah Brosnan: How Do Primates Feel About Their Social Partners?

Alexander Ophir: The Cognitive Ecology of Monogamy

Michael Hendricks: Integrating Action and Perception in

a Small Nervous System

PANEL: Primates, Voles and Worms

WORKSHOP: Jonathan Birch: Animal Sentience and the

Precautionary Principle

Malcolm MacIver: $\underline{\text { How Sentience Changed After Fish }}$

Invaded Land 385 Million Years Ago

Sarah Woolley: Neural Mechanisms of Preference in

Female Songbird

Simon Reader: Animal Social Learning: Implications for

Understanding Others

PANEL: Sea to Land to Air

WORKSHOP: Steven M. Wise: Nonhuman Personhood

Tomoko Ohyama: Action Selection in a Small Brain

(Drosophila Maggot)

Mike Ryan: "Crazy Love": Nonlinearity and Irrationality in Mate Choice

Louis Lefebvre: Animal Innovation: From Ecology to

Neurotransmitters

PANEL: Maggots, Frogs and Birds: Flexibility Evolving

SPECIAL EVENT: Mario Cyr: Polar Bears

Colin Chapman: Why Do We Want to Think People Are

Different?

Vladimir Pradosudov: Chickadee Spatial Cognition

Jonathan Balcombe: The Sentient World of Fishes

PANEL: Similarities and Differences

WORKSHOP (part 1): Gary Comstock: A Cow's Concept

of Her Future

WORKSHOP (part 2): Jean-Jacques Kona-Boun: Physical

and Mental Risks to Cattle and Horses in Rodeos
Joshua Plotnik: Thoughtful Trunks: Application of Elephant Cognition for Elephant Conservation

Lori Marino: Who Are Dolphins?

PANEL: Mammals All, Great and Small

Larry Young: The Neurobiology of Social Bonding, Empathy and Social Loss in Monogamous Voles WORKSHOP: Lori Marino: The Inconvenient Truth About Thinking Chickens

Andrew Adamatzky: Slime Mould: Cognition Through

Computation

Frantisek Baluska \& Stefano Mancuso: What a Plant

Knows and Perceives

Arthur Reber: A Novel Theory of the Origin of Mind:

Conversations With a Caterpillar and a Bacterium

PANEL: Microbes, Molds and Plants

WORKSHOP: Suzanne Held \& Michael Mendl: Pig

Cognition and Why It Matters

James Simmons: What Is It Like To Be A Bat?

Debbie Kelly: Spatial Cognition in Food-Storing

Steve Phelps: Social Cognition Across Species

PANEL

WORKSHOP: To be announced

Lars Chittka: The Mind of the Bee

Reuven Dukas: Insect Emotions: Mechanisms and

Evolutionary Biology

Adam Shriver: Do Human Lesion Studies Tell Us the Cortex is Required for Pain Experiences?

PANEL

WORKSHOP: Delcianna Winders: Nonhuman Animals in Sport and Entertainment

Carel ten Cate: Avian Capacity for Categorization and

Abstraction

Jennifer Mather: Do Squid Have a Sense of Self?

Steve Chang: Neurobiology of Monkeys Thinking About

Other Monkeys

PANEL

WORKSHOP: The Legal Status of Sentient Nonhuman Species 